\title{
Elevated hsa-miR-99a levels in maternal plasma may indicate congenital heart defects
}

\author{
LARS KEHLER, ORSOLYA BIRO, LEVENTE LAZAR, JANOS RIGO JR and BALINT NAGY
}

First Department of Obstetrics and Gynecology, Semmelweis University Budapest, H-1088 Budapest, Hungary

Received May 6, 2015; Accepted August 4, 2015

DOI: 10.3892/br.2015.510

\begin{abstract}
The current standard for prenatal screening is mostly based on biochemical marker tests and the use of ultrasonography. There is no secure stand-alone screening marker for congenital heart defects (CHDs). MicroRNAs (miRNAs) that are associated with cardiogenesis enter the maternal peripheral bloodstream during pregnancy and allow non-invasive prenatal testing (NIPT). The present study investigated the plasma expression profile of fetal hsa-miR-99a in maternal blood. Peripheral blood samples were collected from 39 pregnant patients, comprising 22 with CHD-positive fetuses and 17 with CHD-free controls. miRNAs were isolated from the maternal serum and reverse transcription-quantitative polymerase chain reaction was carried out to determine the expression of hsa-miR-99a. While the miRNA concentrations were almost identical among the affected and control groups (5.54 vs. $6.40 \mathrm{ng} / \mu \mathrm{l})$, significantly upregulated hsa-miR-99a levels were identified in the affected group $\left(1.78 \times 10^{-2} \pm 3.53 \times 10^{-2}\right.$ vs. $\left.1.09 \times 10^{-3} \pm 3.55 \times 10^{-3} \mathrm{ng} / \mu 1, \mathrm{P}=0.038\right)$ In conclusion, according to the present study, hsa-miR-99a is involved in cardiac malformation and may serve as a biomarker during fetal development, and therefore presents as a candidate for monitoring cardiomyogenesis and potential use as a NIPT-biomarker for fetal CHD.
\end{abstract}

\section{Introduction}

Congenital heart defects (CHDs) represent the most common form of major birth defects currently affecting $1 \%$ of live births (1). The introduction of reliable markers for early screening and identification of CHDs is likely to reduce the morbidity and mortality of the affected neonates, the economic burden placed on the National Health Service (NHS) and the stress placed on families, including proactive medical

Correspondence to: Dr Balint Nagy, First Department of Obstetrics and Gynecology, Semmelweis University Budapest, 27 Baross Street, H-1088 Budapest, Hungary

E-mail: nagy.balint@noil.sote.hu

Key words: microRNA, congenital heart defects, non-invasive prenatal diagnosis, fetal diagnosis treatment and parental counseling regarding options during the pregnancy following detection.

The present detection methods of screening CHDs comprise fetal echocardiography and various biomarkers, such as $\beta$-human-chorionic-gonadotropin $(\beta-h C G)$ and pregnancy-associated plasma protein A (PAPP-A); however, none of them establish specific indices without high incidences of false-positive results. Recent studies have identified specific microRNAs (miRNAs) associated with cardiogenesis, linked positively to placental miRNA expression. Detection of these in maternal peripheral blood during pregnancy allows for novel biomarkers used for screening and validating fetal CHDs.

While the reported birth prevalence differs worldwide, the estimate of 8/1,000 live births is generally accepted as the best approximation (1). Rosano et al (2) linked $20 \%$ of infant fatalities to anomalies present at birth; CHDs account for $28 \%$ of mortalities during the neonatal period and $50 \%$ in the first 2-12 months of life $(2,3)$.

Studies have reported $25-50 \%$ of cases with CHD as severe, requiring invasive diagnostics, and one or more surgical procedures within the neonatal period or during infancy $(4,5)$. Frequently, the affected children struggle with more than heart disease due to the associated defects in other organ systems and substantial neurodevelopmental problems (6). In a statement of the American Heart Association, Marino et al (7) reported moderate to severe neurodevelopmental disabilities in $>50 \%$ of neonates born with severe cardiac defects and in $25 \%$ of those with less severe malformations.

Prenatal ultrasonography (US) constitutes one of several standard-screening tools in current obstetric care. Routinely performed at gestational weeks 18-20, fetal echocardiography indicates CHDs by examination of a four-chamber view and additional visualization of the outflow tracts of great vessels and the aortic arch.

While experienced US operators approach sensitivities close to $60-100 \%$ for diagnosing major CHDs in the second and third trimester, general screening specificity and sensitivity differ significantly (8). Although high in tertiary care, such as university-associated hospitals, detection rates drop to $\leq 39 \%$ when performed in community-based centers or by less experienced operators $(9,10)$.

Among the various biomarkers currently available, the assessment of nuchal translucency prevails as one of the most popular screening markers for cardiac malformations (11). Regularly performed between gestational weeks 11-14, 
measurement of the hypoechogenic space between skin and subcutaneous tissue, covering the cervical spine of the fetus, quantifies the risk for possible cardiac malformations. However, the sensitivity of this screening method depends profoundly on the percentile used as the cut-off point and the experience of the US operator conducting the examination $(12,13)$.

A different approach utilizes maternal serum markers, including elevated levels of free $\beta$-hCG and lowered levels of PAPP-A, commonly used for screening Down's syndrome (14). Although highly useful in predicting chromosomal abnormalities when combined, these biomarkers fall short in establishing stand-alone indicators for CHDs (15).

In recent years, research of the fetal products that are able to pass the placental barrier and enter the maternal circulation has increased. Numerous studies linked specific miRNAs associated with cardiogenesis to placental miRNA expression $(16,17)$. Similar to cell-free fetal DNA, these miRNAs enter the maternal peripheral bloodstream during pregnancy and allow for non-invasive prenatal testing, thus introducing novel biomarkers for screening and validating congenital heart malformations (18).

miRNAs belong to a recently discovered family of small endogenous non-coding RNAs and constitute an additional level of control in gene expression. Acting as RNA silencers and at the post-transcriptional level, these molecules modify the expression of $30-60 \%$ of human protein-encoding genes $(19,20)$. Approximately 22 nucleotides long, these short, single-stranded RNA molecules interact with their target coding mRNAs to reduce translation by either reducing mRNA stability or inhibiting translation without target degradation (21).

The various locations of the miRNA-encoding genes on the genome allow differentiation to be separated into 3 groups: Intergenic, intronic and exonic miRNAs. While intergenic miRNA genes reside between 2 protein-coding genes with their own promoters and regulatory units, intronic and exonic miRNA genes rely on co-transcription together with their host genes in intron and exon regions, respectively (22).

Deviation of an miRNA-related pathway may lead to serious malformations and/or early death of the affected mammal as shown by Bernstein et al (23) who examined their importance for correct development of mouse embryonic stem cells (ESC) through disruption of the Dicerl gene. In particular, the changing miRNA expression profile during ESC differentiation and the inability of Dicer-deficient ESC to undergo any type thereof, suggest the involvement of miRNAs in the regulation of transcription factors that are essential for cellular differentiation and survival (24).

Therefore, the present study explores hsa-miR-99a as a marker, examined the correlation between hsa-miR-99a and congenital heart malformations, and therefore, established an evidence-based foundation for future use in diagnostics.

\section{Materials and methods}

Patients. A total of 39 pregnant patients with an average age of $31.59 \pm 5.47$ years and an average gestational age of $22.22 \pm 5.20$ weeks were included in the study. The participants were divided on grounds of fetal health and assigned to a control group, containing 17 women with healthy fetuses and a patient group, consisting of 22 women, satisfying the following criteria led to patient group assignment: Positive US indicating one or more congenital heart defects. The Ethical Scientific Board approved the study, patients were informed and they provided signed consent.

Blood sample collection and plasma preparation. Venous blood samples were drawn into $2 \times 9 \mathrm{ml}$ ethylenediaminetetraacetic acid tubes, which were centrifuged at $800 \mathrm{x} g$ at first and subsequently the obtained supernatant was centrifuged at $4,800 \mathrm{x}$ g for an interval of $10 \mathrm{~min}$ at $4^{\circ} \mathrm{C}$, respectively, using an Eppendorf Centrifuge 5810 R (Eppendorf AG, Hamburg, Germany). Following the second centrifugation, the supernatant maternal plasma was stored in $1.5 \mathrm{ml}$ Eppendorf tubes at $-80^{\circ} \mathrm{C}$ for later miRNA extraction and analysis.

miRNA extraction. miRNA was isolated from $300 \mu 1$ maternal plasma using the NucleoSpin ${ }^{\circledR}$ miRNA Plasma kit (Macherey-Nagel GmbH and Co., KG, Düren, Germany). The concentration of total miRNA was measured on a Nanodrop spectrophotometer (Thermo Fisher Scientific Inc., Waltham, MA, USA). The purity of each sample was determined by the ratio absorbance (optical density value $=$ A260/A280) .

Reverse transcription-quantitative polymerase chain reaction (RT-qPCR).RT of $4 \mu 1$ total miRNA was performed by applying cDNA-miScript II RT (Qiagen GmbH, Hilden, Germany), according to the manufacturer's instructions, allowing further amplification. RT-qPCR was performed in a LightCycler II (Roche Diagnostics GmbH, Mannheim, Germany), with the miRCURY LNA ${ }^{\mathrm{TM}}$ Universal RT microRNA PCR kit (Exiqon A/S, Vedbaek, Denmark) in combination with the Roche Master mix (Roche Diagnostics $\mathrm{GmbH}$ ), and preceded the application of hsa-miR-99a-specific primers and the microRNA LNA ${ }^{\mathrm{TM}}$ PCR primer set, (Exiqon A/S) targeting the sequence: 5'-AACCCGUAGAUCCGAUCUUGUG-3'.

The results were normalized using the U6-snRNA miRNA, and the relative expression of hsa-miR-99a in the retrieved plasma samples was analyzed with the $2^{-\Delta \Delta \mathrm{Ct}}$ method. Sample concentrations of hsa-miR-99a and U6 were calculated in proportion to the globin reference gene used in 4 different quantities $(15,1.5,0.15$ and $0.015 \mathrm{ng} / \mu \mathrm{l})$.

Statistical analysis. All the data are expressed as mean \pm standard deviation non-invasive prenatal testing, and analyzed using Microsoft Excel 2011 version 14.4.6 (Microsoft Corp., Redmond, WA, USA). The statistical significance of differentially expressed miRNAs was computed using Student's two-tailed t-test. $\mathrm{P}<0.05$ was considered to indicate a statistically significant difference.

\section{Results}

Concentration of miRNA. The 39 samples had an average miRNA concentration of $5.92 \pm 1.89 \mathrm{ng} / \mu \mathrm{l}$ with a variance of $3.57 \mathrm{ng} / \mu \mathrm{l}$, a median concentration of $5.90 \mathrm{ng} / \mu \mathrm{l}$ and $\mathrm{P}=0.15$. The 22 samples collected from the patient group showed an average miRNA concentration of $5.54 \pm 1.99 \mathrm{ng} / \mu \mathrm{l}$ with a variance of $3.94 \mathrm{ng} / \mu \mathrm{l}$ and median concentration of $5.50 \mathrm{ng} / \mu 1$, while the control group containing 17 samples 
Table I. Concentration of miRNA.

\begin{tabular}{lcc}
\hline Total miRNA concentration & $\begin{array}{c}\text { Patient group } \\
(\mathrm{n}=22), \mathrm{ng} / \mu \mathrm{l}\end{array}$ & $\begin{array}{c}\text { Control group } \\
(\mathrm{n}=17), \mathrm{ng} / \mu 1\end{array}$ \\
\hline Average $\pm \mathrm{SD}$ & $5.54 \pm 1.99$ & $6.40 \pm 1.69$ \\
Median & 5.50 & 5.90 \\
\hline
\end{tabular}

$\mathrm{SD}$, standard deviation.

Table II. Concentration of miR-99a.

\begin{tabular}{lcc}
\hline $\begin{array}{l}\text { miR-99a } \\
\text { concentration }\end{array}$ & $\begin{array}{c}\text { Patient group } \\
(\mathrm{n}=22), \mathrm{ng} / \mu \mathrm{l}\end{array}$ & $\begin{array}{c}\text { Control group } \\
(\mathrm{n}=17), \mathrm{ng} / \mu 1\end{array}$ \\
\hline $\begin{array}{l}\text { Average } \pm \mathrm{SD} \\
\text { Median }\end{array}$ & $\begin{array}{c}1.78 \times 10^{-2} \pm 3.53 \times 10^{-2} \\
6.45 \times 10^{-3}\end{array}$ & $\begin{array}{c}1.09 \times 10^{-3} \pm 3.55 \times 10^{-3} \\
<0.001 \times 10^{-3}\end{array}$ \\
\hline
\end{tabular}

SD, standard deviation.

exhibited an average miRNA concentration of $6.40 \pm 1.69 \mathrm{ng} / \mu \mathrm{l}$ with a variance of $2.86 \mathrm{ng} / \mu 1$ and median concentration of $5.90 \mathrm{ng} / \mu \mathrm{l}$ (Table I).

hsa-miR-99a concentrations. Based upon the normalized U6-snRNA data, the hsa-miR-99a expression profile was normalized as follows: The patient group had an average hsa-miR-99a concentration of $1.78 \times 10^{-2} \pm 3.53 \times 10^{-2} \mathrm{ng} / \mu 1$ with a variance of $1.25 \times 10^{-2} \mathrm{ng} / \mu 1$ and a median concentration of $6.45 \times 10^{-3} \mathrm{ng} / \mu \mathrm{l}$, whereas the control group showed an average hsa-miR-99a concentration of $1.09 \times 10^{-3} \pm 3.55 \times 10^{-3} \mathrm{ng} / \mu 1$ with a variance of $1.26 \times 10^{-5} \mathrm{ng} / \mu 1$ and a median concentration of $<0.001 \times 10^{-3} \mathrm{ng} / \mu 1$. The difference between the 2 groups was significant with $\mathrm{P}=0.038$ (Table II).

The measured and normalized data presented no significant difference for the average concentration of miRNA, however the hsa-miR-99a concentration showed a statistically significant difference in the expression.

\section{Discussion}

In the present study, the plasma expression profile of fetal hsa-miR-99a was investigated in maternal peripheral blood of 22 pregnant patients with CHD-positive fetuses and 17 CHD-free controls by RT-qPCR and differentially expressed miRNAs were identified in affected patients with significantly upregulated miR-99a levels. While there was no significant difference between the isolated miRNA concentrations among the affected and control groups $(\mathrm{P}=0.15)$, significant differences were identified in normalized hsa-miR-99a concentrations between the 2 groups $(\mathrm{P}=0.038)$.

Similarly, studying the role of the miRNAs associated with fetal heart development, Lazar et al (25) analyzed maternal peripheral blood samples and reported increased hsa-let-7c expression levels in cases of cardiac malformations, which is in line with the present observations. Similarly, it is located on the let-7c-cluster on 21q21.1.
Thus far, numerous studies investigated the crucial role of miRNAs in the regulation of cell proliferation and differentiation, formation of complex organ systems, such as the heart, and throughout pregnancy. While the majority of placental miRNAs expressed during the first trimester exhibit angiogenic features, miRNAs promoting cell differentiation are commonly expressed during the third trimester, suggesting that aberrant expression of miRNAs is likely associated with compromised pregnancies.

Trisomy 21 (Down's syndrome) is caused by the presence of a third copy of the human chromosome 21 (hsa21), which leads to altered expression of its products, causing cardiac malformations, mental deficits and phenotypic deviation as described in recent literature. Located on chromosome 21, the let-7c cluster serves a distinguished regulatory purpose in cardiac and fetal development, with its products targeting mRNAs and thereby precisely modifying organ formation. The present results are in accordance with the published data of Coppola et al (26), in which miR-99a was also overexpressed in CHD samples. hsa-miR-99a is one of its products and therefore a noteworthy candidate for monitoring cardiomyogenesis.

The estimated average medical costs (AMCs) of CHD-affected children $<3$ years of age excess the AMC for non-affected children of the same age by 10-20 times, with the greatest cost difference observed in the care of infants (27). Placing a significant economic burden on the NHS, Connor et al (28) investigated the cost burden of CHD, examined the associations of the social impact on families and reported 'high levels of stress in terms of finances, emotional drain and family member burden.'

These findings emphasize the fundamental importance of early screening on the identification for neonates with moderate or severe CHD, affected families and society in general. Early awareness permits further testing for associated defects in other organ systems, allocation of additional resources for proactive treatment or pregnancy termination after counseling.

Furthermore, studies of the obesity rate among pregnant women indicate a large-scale body mass index increase in the western hemisphere during the last decades, impeding detection further. According to Fuchs et al (29), estimates of maternal obesity range from $10 \%$ in France to $>28 \%$ in the United States of America (29,30). The report concludes that US scans of obese women are feasible, however, they are accompanied by a significant decline in image quality and global anatomical scores, complicating identification of cardiac malformations further. Concisely, the success of fetal echocardiography depends significantly upon maternal obesity, equipment quality and operator proficiency.

Thus, it is reasonable to assume that identification of supplemental methods prior and in addition to second trimester US examination benefit early, accurate and operator-independent assessment of cardiac anomalies significantly. The early awareness and accurate diagnosis of CHDs allow for informed decisions on treatment options, including termination, while appropriate follow-up and delivery in tertiary care centers should improve overall perinatal survival in those pregnancies that continued.

In early embryonic development, following gastrulation and subsequent formation of the 3 germ layers, organ development begins with the formation of the human heart (31). As 
morphogenesis, growth and integrated function are essential for survival and require precise cardiac gene expression, deviations in heart development may result in congenital heart disease, the most frequent form of major birth defects in humans (32).

These pathological alterations present at birth, classified as CHDs, affect the structure and function of the heart. Based on size, location and other associated defects, these malformations differ in severity and determine survival (33).

The crucial role of miRNAs in animal development is best explained by the results of their absence, such as due to the prior mentioned disruption of the Dicerl gene, significantly altering the miRNA formation. Dicerl-deficient mice suffer depletion of functional mature miRNAs and exhibit developmental arrest during gastrulation, causing lethality early in development (23). In particular, cardiac-specific knockout of Dicer later in development results in severe dilated cardiomyopathy, heart failure and postnatal lethality (32).

Organisms contain a large set of different miRNA families within their tissues, with $\geq 1$ miRNA specifically expressed per tissue, such as in muscle or brain (33). While the miRNA-133 family embodies the most abundant miRNA group expressed in muscle tissue, other families, such as the miRNA-1 family, were also positively identified as muscle-specific miRNAs. However, miRNA-208 is the only known miRNA exclusively expressed in cardiac tissue thus far $(34,35)$.

Cardiac and muscle-specific expression of the highly conserved miRNA-1 (miRNA-1-1, miRNA-1-2 and miRNA-206) and miRNA-133 (miRNA-133a, -133a-2 and miRNA-133b) families follow a strict spatiotemporal pattern in vertebrates (35). In a gain-of-function study by Chen et al (35), overexpression of miRNA-1 in transgenic Xenopus laevis led to thin-walled ventricles due to premature myocyte differentiation and lethality in early embryonic development. Concordantly, overexpression of miRNA-1 in developing Xenopus laevis resulted in accelerated myogenic differentiation and decreased cardiac tissue proliferation, and while the exact target structures differ, misexpression of miRNA-133 also led to pathological tissue formation, frequently including disorganized looping and chamber formation (36).

The cardiac-specific miRNA-208 family (miRNA-208a, miRNA-208b and miRNA-499) induces similar pathological conditions in hosts following overexpression, such as gain-of-function studies in mice with miRNA-208a misexpression induced cardiac hypertrophy and conduction deficits (36).

While current research on miR-99a is rare or generally focuses on the oncological role, there are only a few studies regarding the role of $\mathrm{miR}-99 \mathrm{a}$ in heart development and function. Of those, the majority focus on its role in recovering from myocardial infarction when miR-99a is overexpressed. The present study shows the overexpression of miR-99a in the maternal plasma of CHD fetuses. More extensive investigations are required to identify reliable miRNA-based biomarkers for the prenatal detection of CHDs.

In conclusion, in order to evaluate the role of miRNAs in the development of CHDs, the present study found differentially expressed levels of hsa-miR-99a from pregnant patients positively screened for fetal CHD and pregnant women without any signs of fetal malformation. miR-99a is a prospective novel biomarker that provides valuable information for further research of predictive markers and possible therapeutic target structures of cardiac malformation at a molecular level.

\section{References}

1. Bernier PL, Stefanescu A, Samoukovic G and Tchervenkov CI: The challenge of congenital heart disease worldwide: Epidemiologic and demographic facts. Semin Thorac Cardiovasc Surg Pediatr Card Surg Annu 13: 26-34, 2010.

2. Rosano A, Botto LD, Botting B, Mastroiacovo P and Germany W: Infant mortality and congenital anomalies from 1950 to 1994: An international perspective. J Epidemiol Community Health 54: 660-666, 2000

3. Yang Q, Chen H, Correa A, Devine O, Mathews TJ and Honein MA: Racial differences in infant mortality attributable to birth defects in the United States, 1989-2002. Birth Defects Res A Clin Mol Teratol 76: 706-713, 2006.

4. Moller JH, Taubert KA, Allen HD, Clark EB and Lauer RM: Cardiovascular health and disease in children: Current status. A Special Writing Group from the Task Force on Children and Youth, American Heart Association. Circulation 89: 923-930, 1994.

5. Dearani JA, Mavroudis C, Quintessenza J, Deal BJ, Backer CL, Fitzgerald P, Connolly HM and Jacobs JP: Surgical advances in the treatment of adults with congenital heart disease. Curr Opin Pediatr 21: 565-572, 2009.

6. Hoffman JI: The global burden of congenital heart disease. Cardiovasc J Afr 24: 141-145, 2013.

7. Marino BS, Lipkin PH, Newburger JW, Peacock G, Gerdes M, Gaynor JW, Mussatto KA, Uzark K, Goldberg CS, Johnson WH Jr, et al; American Heart Association Congenital Heart Defects Committee, Council on Cardiovascular Disease in the Young, Council on Cardiovascular Nursing, and Stroke Council: Neurodevelopmental outcomes in children with congenital heart disease: Evaluation and management: A scientific statement from the American Heart Association. Circulation 126: 1143-1172, 2012.

8. Rasiah SV, Publicover M, Ewer AK, Khan KS, Kilby MD and Zamora J: A systematic review of the accuracy of first-trimester ultrasound examination for detecting major congenital heart disease. Ultrasound Obstet Gynecol 28: 110-116, 2006.

9. Tegnander E and Eik-Nes SH: The examiner's ultrasound experience has a significant impact on the detection rate of congenital heart defects at the second-trimester fetal examination. Ultrasound Obstet Gynecol 28: 8-14, 2006.

10. Friedberg MK, Silverman NH, Moon-Grady AJ, Tong E, Nourse J, Sorenson B, Lee J and Hornberger LK: Prenatal detection of congenital heart disease. J Pediatr 155: 26-31, 2009.

11. Bruns RF, Moron AF, Murta CG, Gonçalves LF and Zamith MM: The role of nuchal translucency in the screening for congenital heart defects. Arq Bras Cardiol 87: 307-314, 2006 (In English and in Portuguese).

12. Wald NJ, Morris JK, Walker K and Simpson JM: Prenatal screening for serious congenital heart defects using nuchal translucency: A meta-analysis. Prenat Diagn 28: 1094-1104, 2008.

13. Clur SA and Bilardo CM: Early detection of fetal cardiac abnormalities: How effective is it and how should we manage these patients? Prenat Diagn 34: 1235-1245, 2014.

14. Shiefa S, Amargandhi M, Bhupendra J, Moulali S and Kristine T: First Trimester Maternal Serum Screening Using Biochemical Markers PAPP-A and Free $\beta$-hCG for Down Syndrome, Patau Syndrome and Edward Syndrome. Indian J Clin Biochem 28: 3-12, 2013.

15. Jelliffe-Pawlowski LL, Walton-Haynes L and Currier RJ: Using second trimester ultrasound and maternal serum biomarker data to help detect congenital heart defects in pregnancies with positive triple-marker screening results. Am J Med Genet A 146A: 2455-2467, 2008.

16. Latronico MVG, Catalucci D and Condorelli G: MicroRNA and cardiac pathologies. Physiol Genomics 34: 239-242, 2008.

17. Boettger T and Braun T: A new level of complexity: The role of microRNAs in cardiovascular development. Circ Res 110: 1000-1013, 2012.

18. Hahn S and Holzgreve W (eds). Fetal Cells and Fetal DNA in Maternal Blood. Karger, Basel, 2001 
19. Lewis BP, Burge CB and Bartel DP: Conserved seed pairing, often flanked by adenosines, indicates that thousands of human genes are microRNA targets. Cell 120: 15-20, 2005.

20. Friedman RC, Farh KK, Burge CB and Bartel DP: Most mammalian mRNAs are conserved targets of microRNAs. Genome Res 19: 92-105, 2009.

21. Liang Y, Ridzon D, Wong L and Chen C: Characterization of microRNA expression profiles in normal human tissues. BMC Genomics 8: 166, 2007.

22. Chen J and Wang DZ: microRNAs in cardiovascular development. J Mol Cell Cardiol 52: 949-957, 2012.

23. Bernstein E, Kim SY, Carmell MA, Murchison EP, Alcorn H, Li MZ, Mills AA, Elledge SJ, Anderson KV and Hannon GJ: Dicer is essential for mouse development. Nat Genet 35: 215-217, 2003

24. Kanellopoulou C, Muljo SA, Kung AL, Ganesan S, Drapkin R, Jenuwein T, Livingston DM and Rajewsky K: Dicer-deficient mouse embryonic stem cells are defective in differentiation and centromeric silencing. Genes Dev 19: 489-501, 2005.

25. Lazar L, Biro O, Rigo J Jr and Nagy B: Let-7c as potential maternal serum miRNA biomarker in fetal con-genital heart defects. Biomed Rep 158: S8, 2014.

26. Coppola A, Romito A, Borel C, Gehrig C, Gagnebin M, Falconnet E, Izzo A, Altucci L, Banfi S, Anto-narakis SE, et al: Cardiomyogenesis is controlled by the miR-99a/let-7c cluster and epigenetic modifications. Stem Cell Res 12: 323-337, 2014.

27. Boulet SL, Grosse SD, Riehle-Colarusso $T$ and Correa-Villaseñor A: Health care costs of congenital heart defects. In: Congential Heart Defects: From Origin to Treatment. Wyszynski DF, Correa-Villaseñor A and Graham TP (eds) Oxford University Press, New York, NY, pp493-501, 2010.

28. Connor JA, Kline NE, Mott S, Harris SK and Jenkins KJ: The meaning of cost for families of children with congenital heart disease. J Pediatr Health Care 24: 318-325, 2010.
29. Fuchs F, Houllier M, Voulgaropoulos A, Levaillant JM, Colmant C, Bouyer J and Senat MV: Factors affecting feasibility and quality of second-trimester ultrasound scans in obese pregnant women. Ultrasound Obstet Gynecol 41: 40-46, 2013.

30. Weichert J and Hartge DR: Obstetrical sonography in obese women: A review. J Clin Ultrasound 39: 209-216, 2011.

31. Olson EN and Schneider MD: Sizing up the heart: Development redux in disease. Genes Dev 17: 1937-1956, 2003.

32. Chen JF, Murchison EP, Tang R, Callis TE, Tatsuguchi M, Deng Z, Rojas M, Hammond SM, Schneider MD, Selzman CH, et al: Targeted deletion of Dicer in the heart leads to dilated cardiomyopathy and heart fail-ure. Proc Natl Acad Sci USA 105: 2111-2116, 2008

33. Sempere LF, Freemantle S, Pitha-Rowe I, Moss E, Dmitrovsky E and Ambros V: Expression profiling of mammalian microRNAs uncovers a subset of brain-expressed microRNAs with possible roles in murine and human neuronal differentiation. Genome Biol 5: R13, 2004.

34. Zhao Y, Samal E and Srivastava D: Serum response factor regulates a muscle-specific microRNA that targets Hand2 during cardiogenesis. Nature 436: 214-220, 2005

35. Chen JF, Mandel EM, Thomson JM, Wu Q, Callis TE, Hammond SM, Conlon FL and Wang DZ: The role of microRNA-1 and microRNA-133 in skeletal muscle proliferation and differentiation. Nat Genet 38: 228-233, 2006.

36. Callis TE, Pandya K, Seok HY, Tang RH, Tatsuguchi M, Huang ZP, Chen JF, Deng Z, Gunn B, Shumate J, et al: MicroRNA-208a is a regulator of cardiac hypertrophy and conduction in mice. J Clin Invest 119: 2772-2786, 2009. 